\title{
Teknokultura
}

ISSNe: $1549-2230$

http://dx.doi.org/10.5209/TEKN.59757

\section{Ni tan “damas” ni tan "de pedir”. Negándonos a ser víctimas}

\author{
Gloria G. Durán ${ }^{1}$
}

Recibido: 1 de abril de 2018 / Revisado: 26 de junio 2018 / Aceptado: 24 de agosto de 2018 Open peer reviews

Resumen. Dice Santiago Alba Rico que asumir la condición de víctima para tener voz como sujeto político no debería ser el camino hacia una sociedad más justa. Sin duda estamos de acuerdo y por ello hacemos en este artículo un recorrido histórico por todas aquellas feministas que gritaron sus derechos y exigieron esa nueva sociedad por venir. Arrancando en la petición de damas de la Revolución Francesa en la que, como su mismo nombre indica, unas damas pedirán la abolición total de los privilegios de los hombres hasta las Pussy Riots descubrimos a las sufragistas, con Emmeline Pankhurst Goulden, seguimos con las Black Panthers, con Angela Davis, y las Brown Berets, con Gloria Arellanes, las Riot Grrrl y sus corolarios Pussy Riots y Guerrilla Girls. Antes de arrancar nuestro recorrido de lenguaraces obstinadas y guerreras recordamos que también en la revolución francesa la elocuencia se hizo muy peligrosa y durante el terror post revolucionario las cabezas de todas las damas que osaran hacer uso público de la razón fueron desgajadas de sus cuerpecitos. Por ello y tras nuestro recorrido nos preguntamos: ¿Es qué no hay otro modo?, a lo que decimos, no, no ha habido otro modo, y quizá siga sin haberlo.

Palabras clave: acción directa; elocuencia; punk; Revolución Francesa; sufragistas.

\section{[en] Nor "ladys" neither "asking for". Refusing to be called victims}

\begin{abstract}
Assuming the condition of the victim, said the philosopher Santiago Alba Rico, is not the best way to be a complete political subject. In fact this condition is not the way to reach a fair society. We agree, that's why in this article we want to go through all those female activists that yelled their rights and did not become victims at all, those who fight for their rights and were even arrested. With the starting point of the French Revolution where the "Ladies petition" was written by some anonymous females to the Pussy Riots. We go through the suffragettes with the leadership of Emmeline Pankhurts Goulden, then the female Black Panthers, with Angela Davis, and the female Brown Berets, with Gloria Arellanes, the Riot Grrrl and last but not least Pussy Riots and the Guerrilla Girls. Before starting our historical trip through this speaks out warriors we remember that it was also in the French Revolution when the perils of eloquence were most active. In fact all those women who used publicly their public reason were guillotined. That's why at the end of the article we ask ourselves if there is no other way to do so. And we answer, no, there is no other way.
\end{abstract}

Keywords: direct action; eloquence; French Revolution; punk; suffragettes.

Sumario. 1. Introducción. 2. La "Petición de Damas". 3. Los peligros de la elocuencia. 4. Sufragistas y lenguaraces. 5. Las Black Panthers y las Brown Berets. 6. Las Dolle Mina (Mad Mina). 7. Riot Grrrl. 8. Conclusión. 9. Referencias.

Cómo citar: G. Durán, G. (2018). Ni tan "damas” ni tan “de pedir”. Negándonos a ser víctimas, en Teknokultura 15(2), 325-338.

1 Universidad Complutense de Madrid (España)

e-mail: gloriadu@ucm.es 


\section{Introducción}

El 21 de febrero de este año 2018 el filósofo Santiago Alba Rico (2018) publicó un artículo al que tituló "Discurso contra las víctimas". Bajo este rotundo título explicaba: "Estamos en un viraje histórico inquietante. Antes nos pensábamos como ciudadanos o como miembros de una clase o incluso como 'españoles' o 'catalanes'; ahora nos pensamos como víctimas, la única condición a la que parece reconocerse existencia política" (Alba Rico, 2018). "Las mujeres, los racializados, los subalternos, los alteronormativos y los jóvenes", afirma Alba Rico, reclaman ahora el ser escuchados por considerarse los damnificados de relaciones de poder injustas y desiguales. Por eso, dice, por pensarse a sí mismos como "víctimas" pueden reclamar a los otros que por una vez escuchen. En principio la inversión de papeles, "los hombres, los blancos, los ricos, los heterosexuales y los viejos" acostumbrados a liderar y ostentar el poder deben callar y por una vez escuchar. La inversión parece aplastantemente lógica.

Ahora bien, Alba Rico extrapola tres problemas inherentes a esta supuesta lógica aplastante. De estos tres problemas me quedo con el último, el tercero y "el verdadero", el problema "de pretender privilegiar, incluso en términos epistemológicos, la condición de víctima". El derecho a hablar se confunde con la validez de los discursos, la obligación del otro de callar se torna penitencia y no se dirige hacia la construcción conjunta de una sociedad más justa. La centralidad política de la "víctima", en realidad, es lo que define al mundo antiguo y a las sociedades mal llamadas "primitivas". Por ello, insiste, el feminismo debe evitar construirse como sujeto político víctima del machismo y debe armarse como proyecto y no como queja y debe estar capacitado para construir un mundo mejor. Todo esto que "debe hacer el feminismo" se basa, o eso le parece, en que de hecho hasta ahora el feminismo se presenta como "víctima", cosa que es un error, como excelentemente argumenta en todo el artículo.

\section{La "Petición de Damas"}

Quizá tenga razón y sin duda su discurso es correcto, no obstante sería pertinente recordar otra historia del feminismo. Un feminismo que no se leyó a sí mismo como víctima y que aún hoy sigue sin leerse como tal. Es un feminismo "indisciplinado, incorrecto, intruso y lenguaraz", como dice habrían de ser los ahora silenciados. Este periplo lenguaraz y sumamente incorrecto arrancaría en la Petición de Damas (Offen, 2015), una petición en 8 puntos que unas damas anónimas escribieran en la inolvidable fecha de 1789. La "Petición de Damas" arranca pidiendo, de buen grado, tener la posibilidad de trabajar con "ustedes" para la gloria y felicidad del pueblo francés. Estamos en las postrimerías del XVIII cuando el índice de alfabetización en mujeres (muy inferior al de los hombres) era mínimo, seguro que las firmantes eran "ladies" pero su petición quiere abarcar a todas las escalas, clases y rangos sociales.

La Petición de las Damas proponía un decreto que incluirá un preámbulo seguido de una serie de proposiciones muy lúcidas que hubieran evitado muchas situaciones de haberse respetado. La primera era clara, proponían abolir todos los privilegios del género masculino, decían, deben abolirse entera e irrevocablemente 
en Francia. Es evidente que esa supuesta naturalización de nuestro eterno estado de subalternidad no estaba tan naturalizado como siempre se ha supuesto, o lo estaba pero se asumía por parte de nosotras, pero no por todas. La petición continuaba diciendo que el sexo femenino disfrutará siempre de la misma libertad, ventajas, derechos y honores que el sexo masculino. La tercera es magnífica, el género masculino no será contemplado, ni tan siquiera a nivel gramatical, como el género más noble, puesto que todos los géneros, todos los sexos y todos los seres deberían ser y son igualmente nobles. La cuarta llamaba la atención sobre lo insultante de la disposición, "la esposa es autorizada por el esposo" incluida en contratos, en actos u obligaciones. La quinta, llevar pantalones no será una prerrogativa del sexo masculino. La sexta, no se volverá a vestir de mujer como castigo a los soldados que son tachados de cobardes, serán declarados asexuados. En séptimo lugar, todas las mujeres deben ser admitidas en las asambleas de distrito, y han de ser elevadas a responsabilidades municipales e incluso como diputadas de la asamblea nacional. Las restantes insistían en que todas las mujeres podrán ser nombradas magistradas y lo mismo se aplicará a todas las posiciones, compensaciones y dignidades militares. En suma, esta magnífica Petición de Damas solo tiene un leve inconveniente, su título. No tendrían que haber sido tan finas, no habrían de haberse comportado tan "a lo dama" tampoco tan "de pedir", visto con perspectiva creo que habrían de haber exigido tales puntos rotunda y contundentemente, como intrusas indisciplinadas. Esta petición quedó perdida y sepultada entre los papeles de la Asamblea General Revolucionaria.

\section{Los peligros de la elocuencia}

De hecho toda esa potencia primitiva de las mujeres se fue aplacando por necesidad y supervivencia. Carla Hesse (2015) nos recuerda al trabajar lo que ella llama La otra ilustración, cómo las mujeres se volvieron modernas cómo ser elocuente se tornó muy peligroso en la revolución y cómo fuimos perdiendo lúcidas cabezas al ritmo que el terror inundaba París.

En la primavera del 1793 en el punto más álgido de la crisis revolucionaria, Jeanne-Catherine Clere, borracha como una cuba se pone a cantar a pleno pulmón algo como "ha sido un error matar al rey tendríamos que haber matado a la reina que era mucho más culpable que él" (Hesse, 2015, p.9). Tras recibir una buena patada en el trasero, Jeanne-Catherine se verá abandonando el local por los aires. Pocos días después repetirá sus cánticos, esta vez con un contundente "!Viva el rey!", los camareros, que la conocen, le advierten de la peligrosidad de decir eso en las calles, le advierten que si va por ahí gritando esas cosas acabará con sus huesos en el calabozo. Como era de prever eso fue exactamente lo que pasó. E1 7 de marzo de 1793 Mme Clere se verá arrastrada a la jefatura de policía de su sección por una ciudadana revolucionaria convencida. Durante horas Mme Clere continuará cantando y desbarrando hasta caer rendida y exhausta. Cuando despierta estaba entre rejas y acusada de alta traición a la República.

El 8 de abril Mme Clere será conducida al recién constituido tribunal revolucionario. Este intentará dilucidar de dónde salen esas canciones tan supuestamente agresivas para el nuevo régimen. Ella había olvidado cualquier canción ya que una 
vez pasada la cogorza su mente había quedado en blanco, ahora bien, era hija de un guardia del rey, por lo tanto en algún lugar de su cerebro las tonadillas de su infancia debían habitar y de hecho se dispuso a demostrar al tribunal su acervo de letras y cancioncillas. Además recordó que había leído algo en algún periódico cuando su jefe le enviaba a quemarlo, por lo tanto, y dado que eran ya noticias publicadas, no veía mal alguno en repetirlas, incluso a viva voz, por las calles de París. Ella alegó que no había malicia, que tan solo ejercía de altavoz de lo que de hecho estaba pasando, y se declaró súbdita de la República. Tras varios interrogatorios a aquellos que la conocían concluyeron que efectivamente era un poco borrachita pero que estaba "más informada y mucho mejor articulada de lo que aparentaba", que incluso borracha era capaz de pensar con claridad. En abril es acusada formalmente de haber ridiculizado a Robespierre y compañía y también de haber querido re-establecer la monarquía. La ciudadana y trabajadora Jeanne-Catherine Clere es guillotinada el día 19 de abril de 1793 en la Plaza de la República.

La cuestión es, ¿por qué es tan peligrosa?; ¿sería una de las redactoras de esa Petición de Damas tan anónima y tan lúcida? ¿representará ese sector de la población incontrolado e incontrolable que es mucho más listo de lo que debería ser, que además sabe leer, por lo tanto pensar y así pues hablar en público con lucidez? Jeanne-Catherine Clere fue el primer convicto por "traición a la República" del tribunal revolucionario, era mujer y su crimen fue un supuesto "discurso sedicioso". Los discursos públicos acalorados y tocantes a cualquiera tema político, y llevados a término por una mujer serán considerados como especialmente peligrosos y dignos de la mayor atención por las autoridades revolucionarias. Esta peligrosidad era igual de intensa en ambos vértices del espectro social femenino. Como suele pasar son igual de peligrosas las pescaderas leídas y las salonnières o aristócratas capaces de pensar por sí mismas. Lo importante es que desde el arranque de la revolución el "discurso sedicioso" será mucho más criminalizado que cualquier otra forma de expresión política.

La otra dama que se sitúa en el otro lado del espectro social y que es mucho más reconocida es Olympe de Gouges (1748-1793) quien escribiera la Declaración de los Derechos de la Mujer y de la Ciudadanía (1791) planteando una vez más la pregunta clave: "Hombres, ¿sois capaces de ser justos? Es una mujer la que os plantea esta pregunta (...) ¡decidme! ¿Quién os ha dado la autoridad soberana para oprimir a mi sexo?", tardaría poco en llegar al señor Guillotine. Sus panfletos políticos, sus arengas y su defensa de una nueva Francia en la que las mujeres vivieran en justicia, igualdad y fraternidad consiguió que el Tribunal Revolucionario la descabezara exactamente una semana después que Maria Antonieta, el día 3 de noviembre de 1793 (Figura 1). 
Figura 1. Maria Antonieta guillotinada, 1793. Fuente: http://quora.com

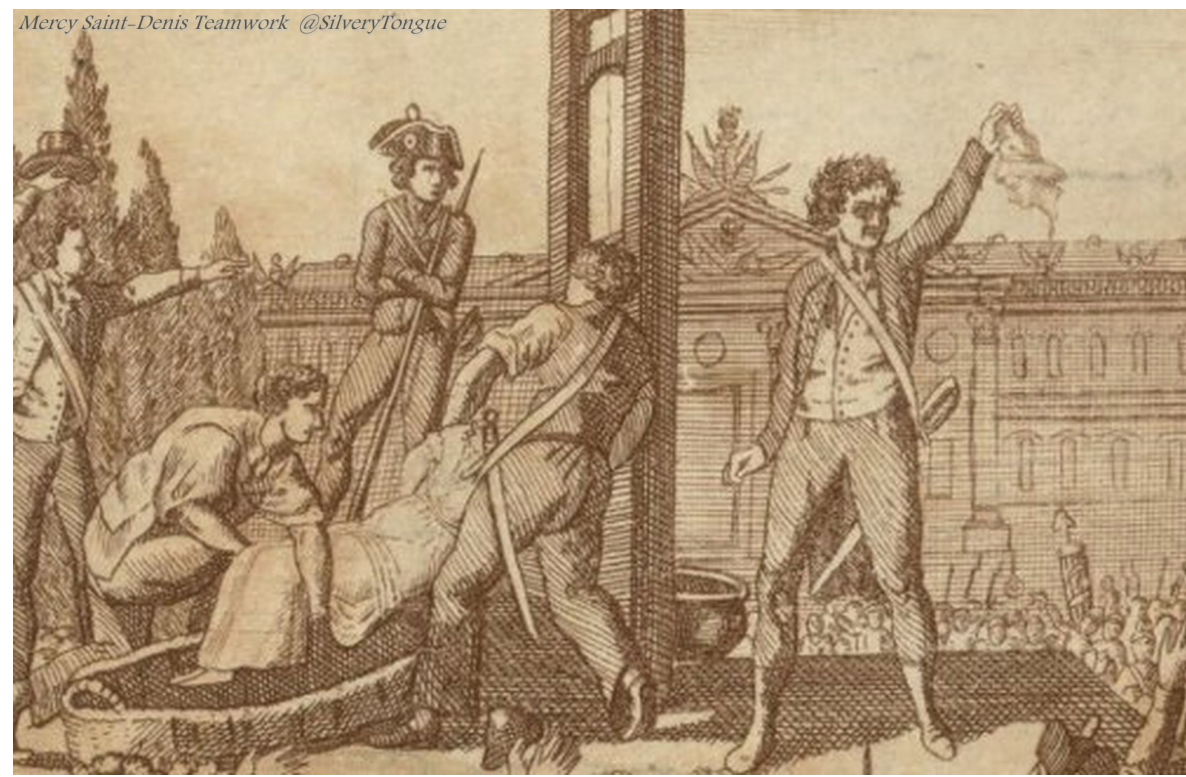

Me parece que el momento aquí relatado es atroz tanto simbólica como realmente. Se criminaliza algo natural al habitar urbano, algo orgánico para hacer ilustración, el debatir públicamente el punto de vista de uno. Mucho más allá incluso que el alegato kantiano en ¿Qué es la ilustración? del uso equilibrado de la razón pública y la razón privada, más allá de la llamada a esa sesuda mayoría de edad, esta criminalización de las mujeres que hablan públicamente será, como bien apunta Hesse, un punto de inflexión para nuestro posicionamiento en la nueva sociedad en ciernes. El desprecio a la oralidad y la peligrosidad de la elocuencia será el primer capítulo en nuestra entrada en la modernidad. El destino terrible de las mujeres más elocuentes durante la revolución francesa hará que el devenir de las reivindicaciones feministas, lejos de ser llevada a cabo por esa víctima a la que se refiere Alba Rico, será asumida por aquellas damas que han preferido pertrecharse de acciones directas y dejar de lado victimismo alguno. Esas mujeres en la vanguardia que han hablado con acciones callejeras, con gritos en pancarta y pasquines. Mujeres gamberras y lenguaraces, mujeres que con sus exóticos actos han llamado la atención y así han logrado traer los problemas que nos incumben a la arena pública procurando que, una vez allí, se mantengan lo suficiente en el foco como para lograr que esa primera petición de damas, esa abolición total de los privilegios de los hombres, se haga efectiva.

\section{Sufragistas y lenguaraces}

Creo fundamental hacer un recuento aun parcial de las mujeres o grupos de mujeres que pasaron a la acción, y que asumieron este ser "indisciplinado, incorrecto, intruso y lenguaraz".

Emmeline Pankhurst Goulden (1858-1928) lo tenía claro, hacía falta tener entrenamiento en la acción directa incluso ser diestra en táctica militar, incluso un siglo antes de ser declarada una de las bellas artes. En 1889 fundará la Women 's Franchise 
League cuyo objetivo será conseguir que las mujeres casadas pudieran votar en las elecciones locales. Pero unos años más tarde, en 1903, cansada ya, decide armar lo que llamará Women's Social and Political Union (WSPU), una organización famosa por las que armaba y por ser la primera cuyas miembras serán bautizadas como suffragette en cierto tono despectivo (Offen, K. 2015). Emmeline será arrestada muchas veces, mantendrá varias huelgas de hambre, y será forzada a alimentarse como lo fueron muchas otras. Djuna Barnes la desconocida más famosa del mundo, viajará a Londres y hará un reportaje que titulará How It Feels to Be Forcibly Fed (Figura 2). Decide vivir esa experiencia, pide ser forzada a tragar una masa con un tubo rojo y un embudo blanco, maniatada por cuatro doctores. Durante todo el artículo nos cuenta la experiencia, completamente espeluznante, y finaliza así:

It was over. I stood up, swaying in the returning light; I had shared the greatest experience of the bravest of my sex. The torture and outrage of it burned in my mind; a dull, shapeless, wordless anger arose to my lips, but I only smiled. The doctor had removed the towel about his face. September 6, 1914 (Barnes, 1914).

Resulta escalofriante el relato y resulta más escalofriante cómo una vez más el resultado, en la historia de una lucha, es acallarnos "forzándonos a tragar" (una vez más lo real y lo simbólico se dan la mano). Emmeline Pankhurst Goulden fue nombrada en 1999 por la revista TIME como una de las 100 personas más importantes del siglo XX, afirmando: "ella moldeó una idea de mujeres para nuestra época; impulsó a la sociedad hacia una nueva estructura de la cual ya no podía haber vuelta atrás" (TIME, 1999). Alentó el sabotaje, la quema de edificios públicos e incluso una suerte de protoescrache al perseguir a determinadas figuras, empleaba tácticas militares para lograr visibilidad y que nuestra voz fuera escuchada. La pregunta hoy día sigue siendo pertinente, ¿es que no había otro modo, no fueron un poco demasiado lejos? Los historiadores difieren en la lectura de su figura, muchos la tachan de vandálica y exagerada, otros de necesaria. Vistos los acontecimientos de nuestra historia reciente yo soy de las que piensan que efectivamente, no había otra manera. Pese a todo, su trabajo es reconocido como un elemento crucial para lograr obtener el sufragio femenino en Gran Bretaña.

Figura, 2. Ilustración para el artículo de Djuna Barnes "How it feels to be forcibly fed". World Magazine, September 6, 1914. Fuente: https://desperadophilosophy.net

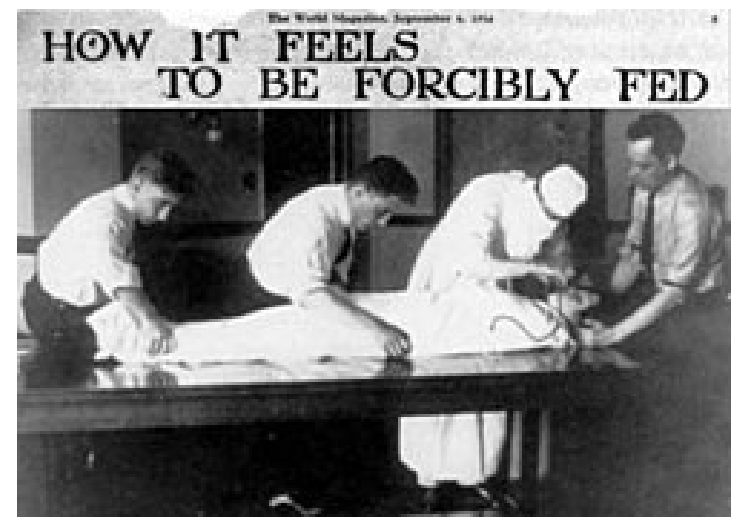


Creo que además de las figuras más destacadas merecería un nota, aunque breve, de la legión de mujeres que poblaron calles y plazas, lugares de alterne, cafés cantantes y tiendas, que paseaban su ser mujer de otro modo. Quizá no tan organizado como las sufragistas pero igualmente efectivo, rozando lo ordinario. Me refiero a las rompedoras de normas y normalidades, muchas mujeres, algunas recordadas en pies de página de la historia, otras ni tan siquiera eso pero sí miembros todas de los cambios contextuales que desde los albores del XX parecieron dar una luz a la nueva mujer que hubo de apagarse tras los dos y devastadores conflictos bélicos. Desde las cupletistas, a las sin sombrero, pasando por las cabareteras, las dadaístas y las salonniéres de vanguardia. De Pilar Cohen a la Baronesa Elsa von Freytag-Loringhoven, de la misma Djuna Barnes a Gertrude Stein y Margaret Anderson, de Maruja Mallo a Emily Hennings. Serían infinitas y también fundamentales.

\section{Las Black Panthers y las Brown Berets}

Volviendo a aquellas que desde un activismo más militante, desde una actitud más beligerante reclamaron nuestros legítimos derechos hemos de dar el salto mortal hasta los años 60. Esa década del verano del amor y de las mil revueltas volvieron a sacar el poderío de esas mujeres que bajo la mística de la feminidad vivieron esos 50 tan duros. Los ejemplos de las integrantes de los Black Panthers y de los Brown Berets añade una capa a este modo otro de reivindicar y exigir una sociedad más justa.

Originalmente llamado Partido de las Panteras Negras para la autodefensa, Black Panther Party for Self-Defense el grupo de activistas por los derechos de los afroamericanos en los Estados Unidos surgirá en Oakland, allí por la brutalidad de la policía y por la necesaria autodefensa frente a la misma. Las mujeres Black Panthers por su parte hubieron de sumar, como decíamos, una capa en su lucha. Hubieron de luchar contra la violencia policial pero también contra el machismo implícito en el partido, doble ración de batalla, dentro y fuera. Elaine Brown y Gwen Robinson fueron las mujeres más involucradas en el partido aunque no cabe duda que la más famosa, cuya implicación fue tangencial, será Angela Davis (Figura 3).

Nació en el 44 en Alabama un lugar idóneo para despertar la rabia de clase y de raza. Al margen del alterego que ya quedó para Birmingham como "Bombingham" tras el bombardeo en la Birmingham Church, del 1963. Davis se hará activista y defensora de los derechos de las mujeres y los afroamericanos en un tiempo en el que "por necesidad" el mundo comenzaba a cambiar. Coqueteará con las Panteras Negras y estará presente en alguna de sus acciones, sin embargo militará en el Partido Comunista de los Afroamericanos de los Estados Unidos, esto es el Che-Lumumba Club. En el artículo A Radical Beatified (2013), de Nicolas Rapold para el New York Times, se analiza la película que reivindica su figura, su título: "Free Angela and All Political Prisoners". Angela Davis como faro de la contracultura y el movimiento de liberación afroamericano, como una excelente oradora, como alguien que actuó sin miedo alguno frente al establisment. Será encarcelada cuando uno de los líderes de los Panteras Negras, George Jackson intentó fugarse en medio de su propio juicio. Un tiroteo, cierta tensión, un muerto, un arma homicida y muchas cartas implicaron a Davis quien acabó en la cárcel durante 18 meses. Pese a todo ella siguió luchando valiente y descarada, para algunos la cara femenina de figuras como Malcolm X o Martin Luther King, y sin embargo muy poco conocida. Hoy es profesora emérita en 
Santa Cruz California y como dice la directora del documental, su presencia sigue irradiando una energía especial a sus 70 años.

Figura 3. Cartel de la película documental de Shola Lynch (2012)

"Free Angela! And all political prisoners". Fuente: http://oukas.info

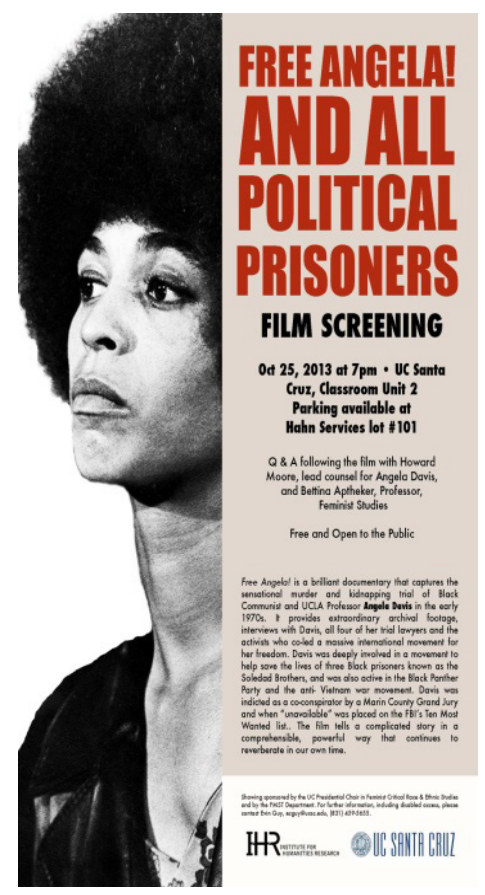

Las Brown Berets, que suelen traducir por las "Boinas Café", no son tan populares, quizá la falta tanto del brazo visual, digamos de un posible "Chicanoxplotation" en el sitio del Blaxploitation como de una cabeza visible ha hecho que no sean tan conocidos y conocidas. No obstante y si una profundiza un mínimo descubrirá que el machismo implícito al Movimiento Chicano hará que este no acabe de funcionar. No cabe duda que las luchas deben ir paralelas, la lucha racial y la feminista, la lucha por una sociedad más justa para todas y todos. Gloria Arellanes será, pese a ello, la primera ministra de las Boinas Café. En 1968 participará en los famosos "walk outs" (Figura 4), o dicho de otro modo, una movilización de la comunidad chicana que a la misma hora de un mismo día abandonó las clases de los institutos de California sumándose unos 15.000 estudiantes. La policía perseguirá a todos los estudiantes implicados en esta salida caminada que anduvieran enredados en los Brown Berets, entre ellos Gloria. La paradoja será que años después ella abandonará al grupo y su militancia, como muchas otras mujeres, por el desprecio que sintieron siempre ya que según sus compañeros “no mostraban una actitud suficientemente Macho”. Esta actitud, la suficientemente macho, parece ser que se refiere al aspecto más beligerante y agresivo. Sin duda una visión simplificada que no repara en que se puede ser radical desde actitudes más sofisticadas e indirectamente efectivas, como la misma Gloria Arellanes demostró en muchas ocasiones. 
Ilustración 4. [Izquierda] "Santa Barbara Brown Berets aka Moratorium in Maravilla" 1970.

Fuente: Oscar Castillo; [Derecha] "Not One More (Chica con boina marrón)” 2016.

Fuente: Rafael Cardenas https://www.4kepics.com/east-l-a-walkouts/

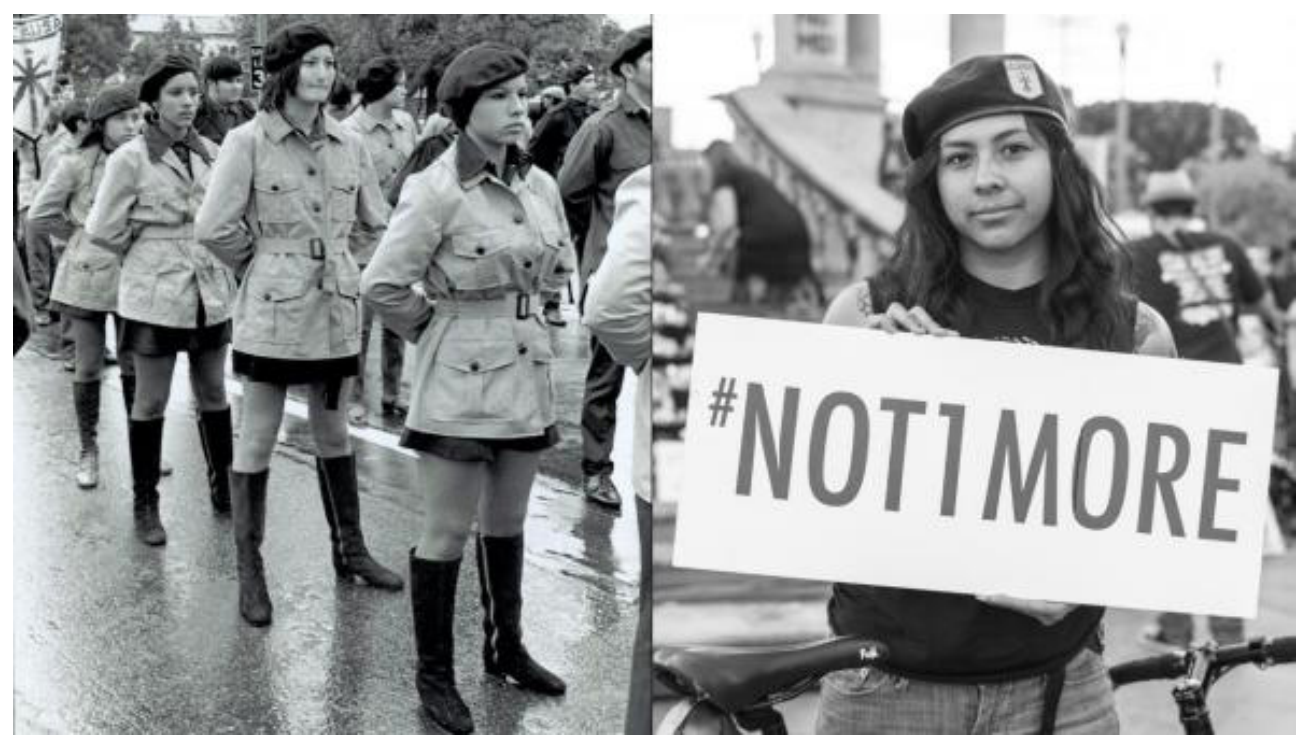

Sin duda la década de la psicología, el movimiento por los derechos civiles, el movimiento en contra de la guerra y, por supuesto, como hemos visto el Black Arts Movement y el Movimiento Chicano serán un escenario y un contexto óptimo para ese gran momento fundacional del feminismo en su segunda ola. El libro de Friedan, The Feminine Mystique (1963) junto con el ya muy extendido Le Deuxième Sexe (1949) de Simone de Beauvoir alentarán en parte la famosa "quema de los sujetadores" liderado por Jaquie Ceballos, entre otras. Este momento que se ha convertido en icónico y cuya imagen se ha reproducido infinitas veces requirió, como no podría ser de otro modo, ciertas dosis de gamberrismo, una acción contundente y tramada social y políticamente, también un poco loca, muy llamativa y cargada de simbolismo. Como la misma Ceballos afirmó en más de una ocasión, "nos dimos cuenta que a la prensa le encantaban estas extravagancias, le gustaba que hiciéramos cosas locas, así que las seguimos haciendo". Con el lema de Kate Millet "lo personal es político" (Millet, 2017) pretenden como aquellas damas, abolir los privilegios de los hombres con la abolición del patriarcado y de los aditamentos que se supone nos caracterizan.

Desde el año 1963 cuando irrumpiera en el mercado, y en el discurso, el libro de Betty Friedan, "La mística de la feminidad", el camino iba preparándose. Esa denuncia clara y directa a la esquizofrenia implícita a la hora de la perfecta mujercita de los años 50, esa divinidad de cintura de avispa incapaz de pensar por sí misma y mucho menos participar en asuntos públicos dará el impulso preciso para que reclamásemos precisamente eso, participar en los asuntos públicos. En unas imágenes de una de las muchas manifestaciones en pro de los derechos de las mujeres del movimiento de liberación feminista Jaquie Ceballos disfrazada de monaguillo arenga a las masas, reza y le pide a la iglesia a viva voz, con un toque muy artivista, que recapacite, que cambie su actitud con las mujeres. "Si Dios creó a la mujer a su imagen y semejanza, por qué 
sale tan mal parada?". Al poco tiempo decidieron actuar, así que en la convención de Miss América en el año 1968 hicieron su pequeña manifestación performativa, una acción lúdico-festiva, eternamente renombrada y muy efectiva, también muy inspiradora para artistas, activistas, performeras y demás damas subversivas e imprevisibles. Era Atlantic City, la convención reunía a miles de mujeres, y las feministas allí reunidas sumaban 150. Y simbolizando el desacuerdo con esta idea del irrespirable corsé de la belleza perfecta que supuestamente debemos tener tomaron un verdadero corsé, una de verdad, un bra (o sujetador) para ser más exactos, y lo quemaron. Y quemaron muchas más cosas, quemaron cremas, y quemaron perfumes, y medias y pantys, y bragas y lazos, fajas y rulos, pinzas y pinta labios. La frase Burning Bra, el sujetador en llamas, y al contenedor de todo le llamaron "la papelera de la libertad".

\section{Las Dolle Mina (Mad Mina)}

En Europa y también por esas fechas no íbamos a la zaga, unas holandesas que se autodenominaban "la loca de Mina", Dolle Mina (Mad Mina) desarrollaban un activismo de base con acciones directas en las calles de Amsterdam (Figura 5). Su táctica consistía en acosar a los hombres con los que se cruzaban, les silbaban, les gritaban supuestos halagos hasta resultar asfixiantes. El uso de lo cotidiano tergiversado pone el foco sobre la agresividad que muchos hombres ejercitan cotidianamente con naturalidad. Las Dolle Mina trabajan desde el poder subversivo del humor y la caricaturización o más bien exageración de aquello que la sociedad lee como natural aun siendo de un atroz machismo. Así desde la parodia pedían igualdad salarial, derecho al aborto y sobre todo exigían que las luchas sindicales incluyeran a las mujeres. En una feria que llamaron "la Feria de la Discriminación" ("Discrimination Fair") jugaban a llamar la atención sobre todas las discriminaciones que vivían con un tono lúdico en una Holanda, la de los años 70, que se negaba a firmar la Convención Internacional del Trabajo referida a la igualdad salarial para hombres y mujeres.

Figura 5. 1970 Utrecht, Dolle Mina se manifiestan por los derechos para la planificación familiar y el aborto. Fuente (C) Spaarnestad, http://hesed.info/blog/feministen.abp
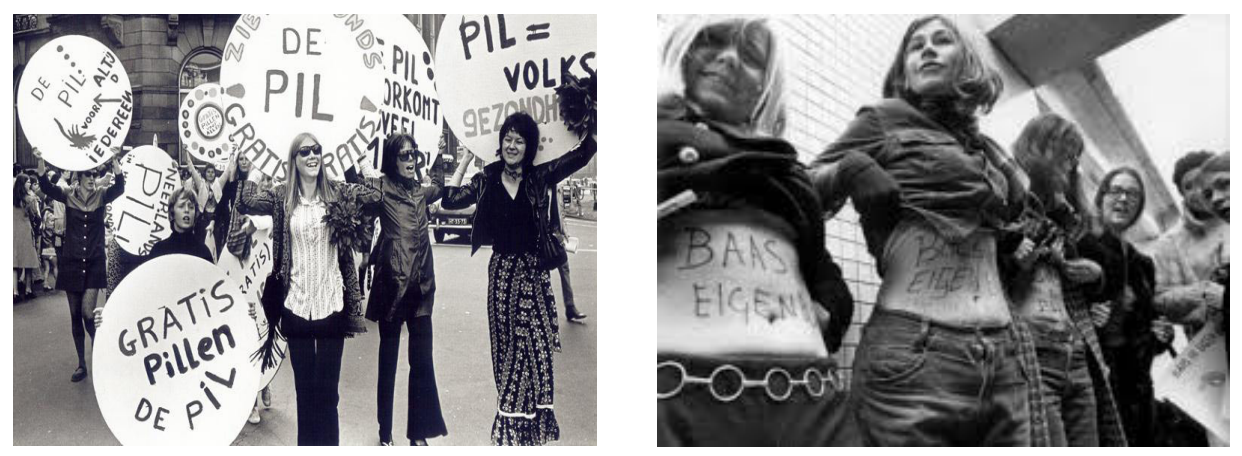

El 23 de enero de 1970 tendrá lugar su primera acción, el ataque sorpresivo a una universidad privada de negocios que solo admitía hombres, la más prestigiosa de Holanda, Nijenrode Castle. Al poco tiempo quemarán un corsé en la estatua de 
Wilhelmina Drucker. Luego clausurarán unos baños públicos, solo para hombres, con lazos rosas. En muy poco tiempo en estos primeros 70 que ya vaticinan el punk muchos fueron los que se entusiasmaron con las locuras de Mina, y por todos los Países Bajos se extendió la fiebre Mina. Se formaron grupos de acción directa en un modelo muy Femen (O'Keefe, 2014) pero pre internet, incluso pre crisis del petróleo. Casi todos los grupos se focalizaban en asuntos como el aborto; los centros de día; las pagas desiguales; los trabajos desiguales; y las madres solteras. También algunos grupos arrancaron una reforma educativa muy importante.

Dolle Mina comenzó a diversificarse y a viralizarse hacia otros formatos a partir de 1975. Hoy sigue siendo muy conocido en los Países Bajos, y sigue siendo un símbolo de la lucha feminista de post guerra. Como reza su biografía, "un grupo de jovencitas con ovarios, que demandaban una cambio con campañas lúdicas que seguro transitarán lo carnavalesco y rabeliano y que queráis poner el mundo patas arriba, topsy-turvy o El pícaro divino o trickster (o las pícaras divinas).

Ese aroma proto punk, que, por otra parte, siempre impregnó a todas nuestras no damas, desde aquellas que pidieran la abolición de los privilegios de los hombres en la Revolución Francesa, o las pescaderas demasiado inteligentes y deslenguadas, a las salonnieres espadachinas de la retórica, y las sufragistas en huelga de hambre obstinada, llegará a partir de los 70 para quedarse. No cabe duda que la proto punk de Baronesa Elsa von Freytrag-Loringhoven (Durán, 2013) fue la abuela de honor de todas las Riot Grrrl, ella podría no saberlo pero no cabe duda que ambas, las Riots y La Baronesa frecuentaron las mismas calles de la misma ciudad mutante, un Nueva York masivo decadente y altamente inspirador.

\section{Riot Girrrl}

Dice Sophie Mayer en su magnífico artículo, "The size of a song: Pussy Riots and the people (power) of poetry" (2013), que las Riot Grrrl se vieron mucho más influenciadas por los textos de las activistas afroamericanas que durante los 80 estuvieron muy activas en Nueva York, que por arengas punks de blancos heterosexuales. Como los Black Panthers, como los Brown Berets, los punks más hegemónicos no resultan menos machistas que los anteriores. Dice que incluso la antológica clave para comprender el surgimiento de las Riot Grrrl (Figura 6) será la de las poetas-mujeres de color que aparecen en This Bridge call my Back: Writing by Radical Women of Color (1983) (traducido al español por Cherríe Moraga, Ana Castillo y Norma Alarcón como Esta puente, mi espalda: Voces de mujeres tercermundistas en los Estados Unidos). En la confluencia de la cultura Do It Yourself(DIY) y el encuentro de las críticas al feminismo mainstream, el reconocimiento de los márgenes, de otras voces, de lo erótico, encontrarían un lugar en un contexto, el de los años 80 , de neoconservadurismo radical.

De hecho el término riot grrrl tiene como origen etimológico unos disturbios llamados Mount Pleasant Race Riots. Jen Smith utilizará la expresión girl riot en una letra de una canción de Allison Wolfe que describía la atmósfera entre las mujeres de la ciudad (Estenson, L. 2012). En unos meses Allison y Molly Neuman, y Kathleen Hannah y Tobi Vail crearon un fanzine que se llamó Riot Grrrl, combinando el riot con el grrrl de otro fanzine anterior que se llamó "Revolution Grrrl Style Now". Luego escribirán su manifiesto como acto fundacional, el "Riot Grrrl Manifesto" en el que afirmarán (entre muchos BECAUSE más): 
BECAUSE in every form of media, I see us/myself slapped, decapitated, laughed at, objectified, raped, trivialized, pushed, ignored, stereotyped, kicked, molested, silenced, invalidated, knifed, shot, chocked and killed (...)

Y remata con el contundente: START A FUCKING RIOT.

Este manifiesto resume a las mil maravillas tanto las reivindicaciones de la tercera ola como el atisbo de la cuarta, pero lo hace con cierta contundencia, acabando con el "arranquemos una jodida revuelta!". La New York University, NYU, conserva con mimo el legado de este movimiento en The Riot Grrrl Collection at the Fales Library. Un archivo que da cuenta de este grupo enorme, desdibujado, bizarro y viral que arrancó en los 80 s y sigue hasta hoy en infinitas formas. Riot Grrrl es un movimiento político y es un movimiento social y es un movimiento artístico, y como tal se mueve. Al hacerlo genera todo tipo de cosas: escritos, performances, declaraciones, poemas, discos, canciones, vestidos, películas, activismos varios, fotografías, videoclips, videos otros, también documentación variada, papeles de proyectos, de acciones activistas, de performances... Batiburrillo de vida, feminismo, activismo punk, teoría queer, cultura $D I Y$, historia de las chapas, de los carteles y flyers, de las camisetas y gorras, de las impresiones sobre todos los soportes, de la ciudad, de la tecnología y de la música. Está dentro de una colección que se llama The Downtown Collection, y que documenta los años 70, 80 y 90 en el SoHo de Nueva York y en el Lower East Side. Casi todos los trabajos que conformaron la ciudad desde abajo eran colaborativos, multidisciplinarios, multimedias y no estaban para nada jerarquizados. Un caldo de cultivo necesario para destacar haciendo más ruido dentro del ruido como sin duda harán unos años después las Pussy Riots, que se conciben a sí mismas como participantes en este Riot Grrrrl.

Figura 6. No todas las mujeres son Riot Grrrrl.

Fuente: Michael Renaud, https://dothebay.com/events/2018/7/1/lip-service-riot-grrrl

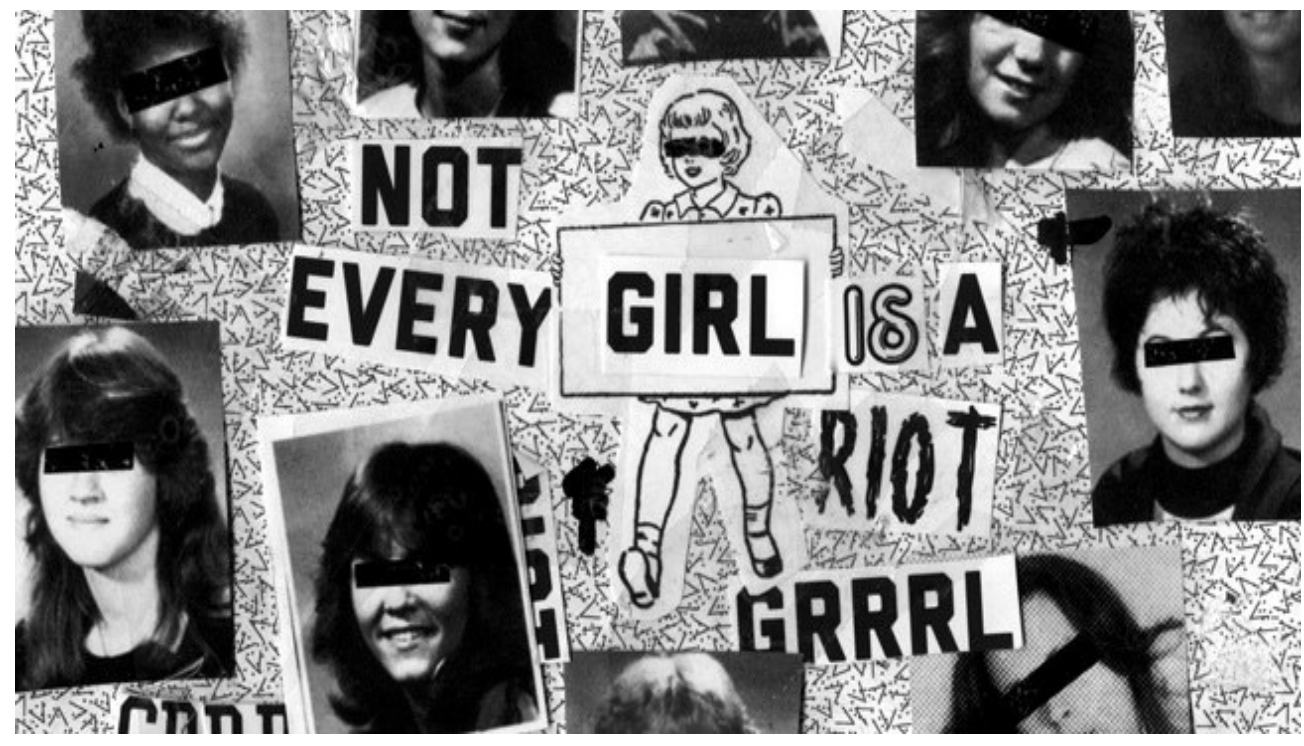


Nadezhda Tolokónnikova, Yekaterina Samutsévich, María Aliójina, parte de la banda Pussy Riots, (spin off del colectivo Voina), fueron acusadas por tocar y cantar esta canción en la Catedral del Cristo Salvador de Moscú:

\author{
Everytime you say no \\ to something that's wrong \\ a crack the size of a hair \& \\ a single note of that song \\ insert itself in the stone \\ the meaning of strong \\ it might take a short time \\ it might take long \\ no \\ no \\ no \\ listen, millions of us \\ singing alonne
}

Ali Smith: "Song”, Catechism, Poems for Pussy Riots.

Este es el rezo punk que puso a las Pussy Riots entre rejas, un rezo a la virgen María para que librara a Rusia de Putin. Es obvio que no nos libramos de él pero la viralización de este acto, tachados por algunos de vandálico y por otros de glorioso, demuestra una vez más que ser mujer y hablar claro puede salir muy caro. Lo interesante del caso, tal como lo analiza Sophie Mayer en The Size of a Song: Pussy Riot and the (people) power of poetry (2013), es que fueron juzgadas de "hooliganismo" ya que el tribunal consideró que su actuación no tenía suficiente calidad artística por lo tanto no podía ampararse en los confortables marcos de la institución arte. Maria Alyokhina escribirá:

Me molestó mucho la puntilla de "así llamado" del fiscal referido al arte contemporáneo. La misma frase se empleó en el juicio del 64 de Brodsky. (...) Nuestras disculpas fueron también consideradas "eso que llaman" y tachadas de insinceras (...) Por lo que a mí respecta este juicio también debería considerarse un "eso que llaman". No me dais miedo. Mi verdad vive conmigo. Creo que la honestidad, la libertad de palabra, y la sed de verdad nos hará más libres. Veremos cómo esto sucede (Mayer S., 2013).

Las otras herederas de las Riot Grrrl, las Guerrilla Girls juegan en otra liga aunque también van enmascaradas y también ejemplifican lo que venimos diciendo, es necesario armarla un poco parda, hacer un poco de ruido para que podamos hablar, para que se nos escuche y para que el mensaje se haga viral. Desde que las Guerrilla empapelasen varias ciudades con la lista de mujeres artistas que ninguno conocíamos muchas comenzamos a buscar a estas mujeres que habían trabajado en el arte y de las que ni un solo profesor nos había hablado. Estábamos terminando la extraña década de los 90 y sabíamos que o cambiábamos nosotras las cosas o nadie lo haría. 


\section{Conclusión}

Aun hoy seguimos pensándolo y aún hoy seguimos peleándolo, una pena que aquella petición de damas del 1789 quedase en un papel perdida. Creo que deberían haberla llamado de un modo más bronco, ni tan "de damas" ni tan "de pedir" y quizá hoy estaríamos en otro lugar.

\section{Referencias}

Alba Rico, S. (2018). Discurso contra las víctimas Diario Público, N. 157. Recuperado de: http://ctxt.es/es/20180221/Firmas/18039/alba-rico-victimas-feminismo-8m-huelga.htm

Barnes, D. (1914, 2 septiembre). How it feels to be forcibly fed. The World Magazine, 2.

De Beauvoir, S. (1949). Le Deuxième Sexe (1949). Paris: Gallimard. (Traducción, Beauvoir, S. de (1969) El segundo sexo. Buenos Aires: Siglo Veinte.

Durán, G. (2013). Baronesa Dandy Reina Dadá. La vida-obra de Elsa von FreytagLoringhoven. Madrid: Díaz \& Pons.

Estenson, L. (2012). “(R)Evolution Grrrl Style Now: Disidentification and Evolution within Riot Grrrl Feminism”. Scripps Senior. Theses. Paper 94. Recuperado de: http:// scholarship.claremont.edu/scripps_theses/94

Friedan, B. (1963). Feminine Mysthique. New York: W.W. Norton. (Traducción, Friedman, B. (1965) La mística de la feminidad. Madrid: Cátedra.

Hesse, C. (2015). The Other Enlightenment. How French Women Became Modern. New York: Princeton University Press.

Mayer, S. (2013, 22 de julio). The size of a song: Pussy Riot and the (people) power of poetry. Soundings, 54, pp. 147-160.

Millet, K. (2017) Política Sexual. Madrid: Cátedra.

Moraga, Ch. y Anzaldúa G. (1983). This Bridge Called My Back: Writings by Radical Women of Colour. NY: Kitchen Table Press.

O'Keefe, Th. (2014). My body is my manifesto! SlutWalk, FEMEN and femmenist protest. Feminist Review, 107, 1-19.

Offen, K. (2015). Feminismos Europeos 1700-1950, una historia política. Madrid: Akal.

Rapold, N. (2013, 4 de abril). A Radical Beatified "Free Angela and All Political Prisoners", by Shola Lynch. The New York Times. 